\title{
What is Theory? \\ Puzzles and Maps as Metaphors in Communication Theory
}

\section{Diana lulia Nastasia and Lana F. Rakow}

Communication Program, University of North Dakota

221 Centennial Drive Stop 7169

Grand Forks, North Dakota, 58202

\begin{abstract}
In this essay, we configure a taxonomy of definitions of and approaches to theory that sorts them by their suppositions or rejection of certain suppositions, rather than by their lineage (disciplinary or methodological traditions) or their focus (levels or areas of inquiry). We categorize definitions and approaches according to the concepts they value and employ, the characteristics and the roles they attribute to theories, and the methodologies and the practical implications they associate with theories, rather than according to what domain of study or school of thought their proponents seem to be affiliated with or to belong to. We have identified a preeminent tendency, theory as puzzle-solving or map-reading, with its varieties science and investigation, that views the object of study or problem as given and taken-for-granted, as exterior to the theorist, overcoming individual theorists, or as more venerable and more important than studying subjectivities. We also explore a counteracting tendency, theory as puzzle-making or mapmaking, with its varieties interpretation and inquiry, that positions the object of study or problem as constructed and disputable, as the theorist's (or theorists') choice and selection, and as separable from and intertwined with and studying subjectivities.
\end{abstract}

Keywords: theory, communication theory, definitions of theory, approaches to theory, classifications of theory, science, investigation, interpretation, inquiry

Acknowledgements: The authors of this article would like to thank the Graduate School at the University of North Dakota for a summer fellowship that supported the collaborative work resulting in several connected communication theory papers and the plan for a communication theory book. An early version of this essay was presented as part of the program of the Philosophy of Communication Division at the annual conference of the International Communication Association in 2009. This division of ICA provided a space for dialogue about the issues raised by the study, and the division's leaders and members offered provided helpful commentaries and suggestions for improvement.

According to Bertrand Russell (1979), the Greek word theorein was used in the Orphic rites with the meaning of "passionate sympathetic contemplation," a state in which the human spectator became identified with the suffering god, with the god's death and rebirth (p. 52). Yet, the notion of theory has been denied "passion" and "sympathy" for a long time, these features having been replaced with "reason" and "objectivity." Ancient theory was born from the encounter of the East and the West; yet modern theory has become a Western construct. Contemporary theory is often associated with rationalism and science, with a human pursuit of describing, explaining, predicting, and controlling a physical and social environment envisioned as fixed and unitary. Yet, there have been attempts to retransform theory from detached to involved, from universal to local. This essay strives to make sense of such discrepancies and paradoxes by providing an overview of the different meanings of theories and trends in theorizing, with reflections on and examples from theoretical developments and possibilities in communication studies.

Many handbooks, books, and articles in communication studies have offered ideas on and statements about what is theory and what makes a theory valuable. Examining this multiplicity of perspectives, various authors have offered classifications of theory relevant to the understanding of communication or within the field of communication. For example, Karl Eric Rosengren (2000) describes four approaches to society, represented on two axes from subject to object and from conflict to consensus (pp. 7- 8), and he attempts a three-dimensional typology of agents of socialization, corresponding to different academic disciplines and studies of communication (p. 14). Denis McQuail (2005) presents five kinds of theory - social scientific, cultural, normative, operational, and common-sense (pp. 
14-15), six levels of communication inquiry societal, institutional/organizational, intergroup, intragroup, interpersonal, and intrapersonal ( $p$. 18 ), and three alternative approaches to communication as science - structural, behavioral, and cultural (p. 20). Robert T. Craig (2007) asserts that a schema of dialogical-dialectical coherence permits discussions of "complementarities and tensions" (p. 66) for his seven traditions of communication theory: rhetorical, semiotic, phenomenological, cybernetic, sociopsychological, sociocultural, and critical. Melvin L. DeFleur (2010) claims there are two types of theories, those that are derived from research and that "consistently describe, explain, and predict what seems to cause specific kinds of events and consequences in the real world" (p. 26), and those that are derived from ideologies and are "deduced from principles that are assumed to be true, ahead of time (before research) as the 'true explanation' or situation" (p. 27).

While we are sympathetic to these efforts to comprehend an otherwise bewildering array of theoretical positions, such typologies often confuse rather than clarify, obfuscate rather than reveal similarities and differences in the positions. In this essay, we configure a taxonomy of definitions of and approaches to theory that sorts them by their suppositions or rejection of certain suppositions, rather than by their lineage (disciplinary or methodological traditions) or their focus (levels or areas of inquiry). In this essay, we categorize definitions and approaches according to the concepts they value and employ, the characteristics and the roles they attribute to theories, and the methodologies and the practical implications they associate with theories, rather than according to what domain of study or school of thought their proponents seem to be affiliated with or to belong to. We argue that authors from across disciplinary and subdisciplinary areas, as well as from across schools and trends, often repeat and thus reify the same assumptions about theory; we also argue that innovative ideas about theory sometimes come from unexpected sources. We examine a preeminent tendency, theory as puzzle-solving or map-reading, with its varieties science and investigation, that views the object of study or problem as given and taken-for-granted, as exterior to the theorist, overcoming individual theo- rists, or as more venerable and more important than studying subjectivities. We also examine a counteracting tendency, theory as puzzlemaking or map-making, with its varieties interpretation and inquiry, that positions the object of study or problem as constructed and disputable, as the theorist's choice and selection, and as intertwined with studying subjectivities.

\section{Theory as Puzzle-Solving or Map- Reading}

In his book "The Structure of the Scientific Revolutions", Thomas Kuhn (1996) attributes the role of puzzle-solving to "normal science," to theory and research "firmly based upon one or more past scientific achievements, achievements that some particular scientific community acknowledges for a time as the foundation for its further practice" (p. 10). Examples of such corpuses of knowledge that become paradigmatic and exemplary are "Ptolemaic astronomy" and "Copernican astronomy," "Aristotelian dynamics" and "Newtonian dynamics," "corpuscular optics" and "wave optics" (p. 10). Such frameworks gain status and acquire success by finding solutions to problems "that the group of practitioners have come to recognize as acute" (p. 23), "by extending the knowledge of those facts that the paradigm displays as particularly revealing," and "by increasing the match between those facts and the paradigm's predictions" (p. 24). Commenting upon the nature of puzzles, on the attributes of scholarly theory and practice as puzzle-making, Kuhn remarks:

Puzzles are, in the entirely standard meaning here employed, that special category of problems that can serve to test the ingenuity or skill in solution. Dictionary illustrations are 'jigsaw puzzle' or 'crossword puzzle,' and it is the characteristics that these share with the problems of normal science that we need to isolate. [...] It is no criterion of goodness in a puzzle that its outcome be intrinsically interesting or important. On the contrary, the really pressing problems, e.g., a cure for cancer or the design of a lasting peace, are often not puzzles at all, largely because they may not have any solutions. [...] Though intrinsic value is no criterion for 
a puzzle, the assured existence of a solution is (pp. 36-37).

It is intriguing that many theory handbooks in communication studies, with writers of diverse educational backgrounds and conceptual orientations, have adopted or adapted the puzzlesolving idea, without the negative connotations attached to it by Kuhn. Stacks, Hill and Hickson (1991) associate theory with architecture, with pre-design, and postulate that "the architect understands the theoretical concept underlying all buildings," and that "communication architects are no different" (p. 283). Cragan and Shields (1998) define theory-makers as puzzle-solvers, and continue: "We cannot resist solving puzzles. Puzzle-solving is in our nature" (p. 4). Katherine Miller (2005) affirms: "We are faced every day with puzzles about communication and social life" (p. 20).

Other authors of communication theory overviews have substituted the metaphor of the puzzle with the metaphor of the map. Em Griffin (2000) contends: "Theories are maps of reality. The truth they depict may be objective facts 'out there' or subjective meanings inside our heads. Either way, we need to have theory to guide us through unfamiliar territory" (p. 4). Heath and Bryant (2000) cite McGuire (1981) who has named theories "maps" and has stated that "Knowledge is not a perfect map of the thing known but without it one has to move through the environment with no map at all" (p. 3). Littlejohn and Foss (2005) maintain: "A theory is like a map of a city on which you can view the streets, housing developments, shopping centers, picnic grounds, and rivers because there is a key that helps you interpret what you see. Similarly, theories function as guidebooks that help us understand, explain, interpret, judge, and act into, in this case, the communication happening around us" (p. 16).

When associating theory with map reading, these diverse examiners of communication scholarship draw on a positivism perspective stemming from Ludwig Wittgenstein and from the Vienna Circle, a group of philosophers and scientists who started gathering at Vienna University in the 1920s. However, the communication metatheorists quoted in the previous paragraph do not doubt the possibility of equating the reading of the map with the comprehension of the territory, whereas Wittgenstein and Vienna Circle thinkers seemed hesitant about the association between map deciphering and territorial conquest. Some of Wittgenstein's statements in Tractatus Logico-Philosophicus (1922), that "propositions represent the existence and nonexistence of states of affairs" and that "the totality of true propositions is the whole of natural science" $(4.1,4.11)$, are similar to those of Griffin (2000), Heath and Bryant (2000), or Littlejohn and Foss (2005); yet many other assertions by Wittgenstein, such as one in Tractatus LogicoPhilosophicus (1922) that "it is possible to devise a picture of the world without saying what it is a representation of" (5.526) or some in Philosophical Investigations (1953) about the multiplicity of language-games and of their meanings, go against the idea that map reading grants certitude about the specific territory assumed to be mapped. Rudolf Carnap (2003), a major figure of the Vienna Circle, affirmed even more firmly that when we look at a map of a railroad we do not find what is out there but rather we get to compare this given map with other maps we might have seen or we have available (p. 25-26). Whereas Wittgenstein and Carnap debate the possibility of connecting the map with the territory, many authors of communication handbooks take the connection for granted.

In addition to not acknowledging the nuances of the conceptions of Kuhn, Wittgenstein, or the Vienna Circle, numerous authors of communication theory do not recognize that the conceptualization of theory as puzzle-solving or mapreading has been sometimes beneficial for the production of human knowledge yet many other times detrimental to the imagination of innovative knowledge possibilities. Theory as puzzlesolving or map-reading promotes a view of the object of study or problem as given and takenfor-granted (see critiques by Agassi, 1975), as exterior to the theorist, overcoming individual theorists, or as more venerable and more important than studying subjectivities (see critiques by Toulmin, 1953, 1990). This approach legitimates a scientific community in becoming the owners and the protectors of the body of knowledge, in deciding which problems have solutions and which ones are insolvable, which maps are meaningful and which ones are meaningless, 
and who are the distinguished members and who are the pariahs of the group (see critiques by Lakatos \& Musgrave, 1968; Lakatos, 1978). Moreover, theory as puzzle-solving or mapreading supports status-quo and disavows opposition, not allowing cross-disciplinary dialogue (see critiques by Woolgar, 1988).

In what follows, we will examine the two varieties of theory as puzzle-solving or map-reading, namely science (truth-seeking) and investigation (fact-seeking).

\subsection{Science (Truth-Seeking)}

We use the term "science" as referring to the type of conceptualization rooted in the GreekRoman antiquity, in the ideals of finding the ultimate truth and of identifying the unique method for reaching the universal being, imposed in the Western world in approximately the $14^{\text {th }}$ century, with the beginnings of laicization, urbanization, industrialization, and technologization, and dominating the Western world until the contemporary period (some say that it has ended; we argue that it is continuing), that shows some signs of tolerance and multiplicity. The definition of theory as science is connected with millennialong Western quests for acquiring and employing a unique and privileged collection of ideas or set of statements capable of granting human beings objectivity and certainty, and capable of allowing human beings to master and manipulate the universe (see critiques by Williams, 1976).

A science that would subsume all the others, and that would explain all that is, originated in the Aristotelian model of a unified methodological system and of a uniform deductive strategy (see Edel, 1982) and has become a paragon for modernity. It has undergone versions ranging from Compte's (1853) hierarchy of domains with the inferior theological stage, the metaphysical stage, and the superior positive stage, to Oppenheim and Putnam's (2000) unity of science as a working hypothesis through microreduction from the higher to the lower levels ending with elemental particles, with physics. For example, introducing his conception of the hierarchy of domains, Auguste Compte (1854) writes: "The first characteristic of Positive Philosophy is that it regards all phenomena as subject to invariable natural laws." According to such conceptions, there is a single, elementary, and unchangeable reality that theories can be further or closer to, and there is a unique, exact, and correct explanation of any given circumstance or rather a single, precise, and accurate solution to any given problem. According to such theorizations, the multitude of perspectives is due to errors in reasoning, and therefore it is inconsequential for the scientist.

For advocates of theory as science, the mathematical, physical, and social sciences are all one and the same, as they all have the same purpose and operate under the same assumptions. For scholars conceiving theory as science, theoretical concepts are laws grouped into immutable structures or systems, the characteristics of good theories are non-complication, verifiability, and replication, and the roles of good theories are explanation of past and present cause-effect chains followed by prediction of future cause-effect chains (see Losee, 1987; Machamer \& Silberstein, 2002). If theory is viewed as science, then the only methodology, or strategy of passage from theory to practice, is deduction, the inference of definitive and stable judgments from completely known and entirely clarified evidence.

Discussing theoretical concepts, Karl Popper (2002) asserts that theories are "universal statements," "nets cast to catch what we call "the world': to rationalize, to explain, and to master it" (pp. 37-38); Abraham Kaplan (1964) affirms that behavioral theories are generalizations, series of laws that are unrestricted as to space and time and are always true (pp. 84-114). Popper (2002) characterizes good theories by falsiability or power to disconfirm false universal propositions, testability or power to confirm true universal propositions (both through measurement against an outer reality), simplicity or clarity for anybody in any circumstance, and probability or believability by everybody in all situations (pp. 57208); Paul Davidson Reynolds (1971) characterizes desirable social theories by abstractness or "independence of space and time", intersubjectivity or "agreement about meaning among relevant scientists," and empirical relevance or "the possibility of comparing some aspect of a scientific statement, a prediction or an explanation, 
with objective empirical research" (pp. 13-18). Karl Popper (2002) attributes to good theories the functions of causal explanation and of deduction of predictions. Hubert Blalock (1969, 1982) argues that sociological hypotheses are mathematical formulas and that social measurements lead to explanation and prediction.

The key words in this approach are laws or general principles, universality or causal necessity, measurement or calculation of simple and understandable cause-effect chains, and control or manipulation of causal relations.

The conceptualization of theory as science has been critiqued for disguising relations of power and intentions of manipulation, and for not welcoming a multitude of realities and a variety of epistemic perspectives. For example, philosopher of science Paul Feyerabend (1994) professes that "interests, forces, propaganda, and brainwashing techniques play a much greater role than is commonly believed in the growth of our knowledge and in the growth of science" (p. 17). Poststructuralist philosopher Michel Foucault $(1965 ; 1972)$ declares that the "normative" has become the "normal" and the "disciplinary" has become the "disciplined" in the science(s), conducive to a history of repressing the "abnormal" and the "undisciplined." Scientists and philosophers have argued that theory devised as science naïvely essentializes and fails to problematize, among other things, race (Cajete, 2000; Jackson, 2002), gender (Harding, 1986; Haraway, 1989; Subramaniam \& Weasel, 2001), and sexuality (Keller, 1985; Graber, 2001; Sullivan, 2003), that it fixates white, masculine, and heterosexual viewpoints as the allencompassing truth, and that it reduces the multiplicity and diversity of human perspectives to a unique and uniform vision.

In spite of critiques, the conceptualization of theory as science has remained overwhelmingly dominant in numerous disciplines, including communication studies. Different authors in the field have defined theory as truth-seeking, as "explanation (power) and prediction (precision)" (Dance \& Larson, 1976, p. 5), as "abstract ideas" and predictable findings" (Chafee, 1996, pp. 15-18), and as "a set of concepts and relationship statements that enables one to understand, describe, explain, evaluate, predict, and control things (phenomena)" (Cragan \& Shields,
1998 , p. 4). Diverse authors in the field have cited Popper, paradoxically by quoting the first half ("Theories are nets cast to catch what we call 'the world'") and forgetting the second part of his definition ("to rationalize, to explain, and to master it"), as well as Kaplan, sometimes associating his ideas with a scientist perspective, but some other times connecting his thoughts to an interpretivist perspective. Intentionally or accidentally, these scholars reify "the orthodox consensus," an extended "model of natural science" (see critiques by Giddens, 1989, p. 56).

The designation of theory as science in communication studies was connected with the configuration of theoretical concepts as laws. Berger (1977) describes the covering law or the general law as having the form "All $X$ is $Y$ " and of having the power of predicting and demonstrating "with $100 \%$ success" an object or phenomenon (p. 8), and states that cultural and temporal variation are reducible and, in many cases, irrelevant (pp. 13-16). This notion, although re-evaluated and critiqued later (for reevaluations of theoretical concepts as laws, see Kochen, 1979; Berger, 1989; for different critiques of theoretical concepts as laws, see Delia, 1977; Smith, 1988), has left a powerful mark of the field. The denomination of theory as science in the field of communication has been linked with universality, with the characterization of theory in terms of simplicity, testability, and intersubjectivity (also named "heurism"), and with causality, with the attribution of explanatory and predictive roles to theory.

It is notable that at least some of the characteristics of theory as formulated by this approach have been appropriated by a number of disparate scholars, not all found in association with a communication as science perspective: Berger and Chaffee (1987) characterize theory by explanatory power (plausibility), predictive power (probability), parsimony (simplicity), falsiability (testability), internal consistency (coherence), heuristic provocativeness (acceptability), and organizing power (innovation) (p. 104); Infante, Rancer, and Womack (2003) characterize theory as simple (easy to understand), parsimonious (simple in structure), consistent with related theories (acceptable by a scholarly community in terms of premises), interpretable (acceptable by a scholarly community in terms of conclusions), 
useful (practical), and pleasing to the mind (aesthetic) (pp. 43-44); Casmir (1994) characterizes theory by appropriateness (ultimate end or purpose), validity (a claim that a theory truly made sense of a phenomenon), scope (degree of generality), parsimony (simplicity), and consistent world view (coherence) (pp. 28-30); Littlejohn and Foss (2005) characterize theory by theoretical scope (comprehensiveness), appropriateness (coherence), heuristic value (innovation), validity (falsiability), parsimony (simplicity), and (concept related with interpretivism than with scientism) openness (pp. 29-30). It is also notable that even authors that, as we argue subsequently, formulate theory as puzzlemaking or map-making, as interpretation or questioning, mention parsimony, falsiability, and heurism as features of theories (see Anderson and Ross, 1994; Wood, 1997).

Because theory has been mainly defined as science in the communication discipline, the movement from theory to practice has primarily been accomplished through a research methodology designed to isolate communication products and to measure their features against those of an all-encompassing model, and to isolate communication acts and to calculate their effects against those of a universally applicable set of functions (see critiques by Peters, 1986; Denzin \& Lincoln, 2003).

\subsection{Investigation (Fact-Seeking)}

We use the term "investigation" as referring to the type of conceptualization that emerged in the Western world in approximately the $19^{\text {th }}$ century, with the abandonment of the metaphysical systems and the disbelief in the absolute truth (see Berlin, 1996), and that continues in the contemporary period with postpositivist and neofunctionalist trends (see Diesing, 1991). It is not accidental that we propose a term associated with the work of the detective or criminologist: the investigator looks for data in support of hypotheses, examines data and hypotheses for flaws and mistakes, and supports data as solid facts and hypotheses as good theories, against numerous competing explanations. In this view, the investigator is an expert, more capable and better trained than other humans; data is cleaner and more reliable if it is based on objectification, on uninvolvement; and change happens because of the development of more sophisticated and more trusted technical means, therefore change in theories occurs because of the accumulation of more data, not because of multiple possibilities and of flexible realities.

The definition of theory as investigation is connected with the Western dispute between the natural and the social sciences, with social scientists emulating physical scientists while attempting to establish their own principles and procedures (see Turner, 1996). The idea of investigators seeking and exploring the facticity of nature, as well as of humans, by developing amendable claims and limited truths, has emerged as philosophers of science conceded that the perfect statement and the ultimate reality are ideals rather than possibilities, and as social scientists have built their own, different visions (see Nathanson, 1963; Bordbeck, 1968; Delanty \& Stydom, 2003). Social analysts distinguished between bodies of knowledge and sets of methods in the natural sciences, referred to as nomothetic, and corpuses of ideas and series of techniques in the social sciences, referred to as ideographic (Nagel, 1952; Von Wright, 1971). According to such conceptions, theories uncover facts, and theories can be good or bad, as they convey more or less accurate data, or as they provide more or less profitable solutions to problems (Hollis, 1994; Benton \& Craib, 2001). The multitude of perspectives is due to the partiality of human knowledge and the perfectability of human instruments, which should be continuously and progressively surpassed.

For advocates of theory as investigation, the mathematical, physical, and social sciences use different tools or instruments in order to provide diverse translations of the same phenomena. For scholars viewing theory as investigation, theoretical concepts are rules grouped into flexible structures or systems, the characteristics of theories are degrees of complication, demonstrability, and continuation, and the roles of theories are successful descriptions of occurrences followed by effective prescription of regularities (Hempel, 1952). If theory is viewed as investigation, then the proper methodologies, or means of transition from theory to practice, is inductive, empirical observation or evidence gathering, 
followed by generalization of particular instances in general classes, considering that circumstances will be in the future as they have been in the past (Polanyi, 1958).

Proponents of defining theory as investigation have asserted that theoretical underpinnings may be at various levels of structural complication and of factual compliance, thus being in different stages of specificity and inclusiveness. Morris R. Cohen (1931) characterized social theories by "their less repeatable character," "their less direct observability," "their greater variability and lesser uniformity," and "their greater difficulty in isolating one factor at a time" (p. 250). Joan Ganz (1971) attributed to theories referring to human behavior the functions of explaining both causal and non-causal relations. Numerous social analysts (Bhaskar, 1979; Knorr-Cetina \& Cicourel, 1981; Cartright, 1989; Archer, 1995) have argued that valid, but improvable data can be obtained through several reliable methodologies for observation and formalization.

The key words in this approach are rules or specific principles, conventionality or logical formalization, observation or careful scrutiny, and prescription or prevision of complex processes and actions.

The conceptualization of theory as investigation differs from the previous one in that it highlights description and prescription of facts rather than explanation and prediction of cause-effect chains, but it resembles the previous one in that it conveys examinations of things exterior to and not decided by examiners, rather than of things interior to and decided by examiners (see Habermas, 1998). This conceptualization abandons the unique truth for the multiple views, yet it has been critiqued for "looking at" instead of "looking behind", for still accepting instead of problematizing the physical and the social life (see Berger, 1963). This approach recognizes in principle difference and diversity, yet it has been critiqued for reducing these, in practice, to uniformity, for still privileging a limited number of hierarchically organized voices, for still silencing minority and non-Western groups (see Adorno, 1976; Sedgwick, 1990).

The conceptualization of theory as investigation has been posited as an alternative to the designation of theory as science in several dis- ciplinary areas, including communication. Authors in the field have defined theory as factseeking, as "any attempt to explain or represent an experience" or "an idea of how something happens" (Littlejohn, 2002, p. 2), as "a speculation, a conjecture, or an informed guess about how things work, or why certain events happen, or why certain events follow other events" (Baldwin, Perry \& Moffitt, 2004, p.8), as "descriptions of phenomena in the social world," "relationships between these phenomena," "an underlying and abstract storyline that describes the mechanisms at work in these relationships," or "links between the storyline and the observed phenomena and relationships" (Miller, 2005, p. 22). Miller cites Phillips (1992), a sociologist who approaches theory as investigation, who wrote: "There is no ordained correct usage, but we can strive to use the word consistently and to mark directions that we feel are important." Various authors in the field have distinguished between nomothetic science and ideographic science, Naturwissenschaften and Geisteswissenschaften, "causal analysis and analysis by reasons" (Hanna, 1982, p. 29), prediction and prescription, or certainty and probability. This is a distinction between science and investigation, or between truth-seeking and fact-seeking.

Theory as investigation in communication studies was linked to theoretical concepts as rules. Cushman (1977) affirms that the rules perspective "extends the legitimate range of scientific invention from causal to practical regularities and focuses attention on the manner in which such regularities manifest increasing levels of complexity" (p. 38). Shimanoff (1980) treats rules as descriptions-prescriptions of acts that are "followable," "prescriptive," "contextual," and "pertaining to behavior" (pp. 37-57). McLaughlin (1984) defines rules as "propositions [...] which model our understandings of what behaviors are prescribed or prohibited in certain contexts" (p. 21), and mentions among the characteristics of rules that they "can be followed" or "can be broken," that they "have no truth-value," that they are "conditional, but more general than the circumstances they cover," and that they are "indeterminate and negotiable" (pp. 18-21). Various rules are deemed to determine different possibilities of observation or different research methodologies. 
In addition, different scholars in the discipline affirm that theories function to organize experience, to extend knowledge, to stimulate and guide further research, and to perform an anticipatory role. Almost any theory and research handbook or book in and across the discipline of communication refers to hypothesis assessment, operationalization of variables, sampling, measurement, reliability checking, and hypothesis testing (see Lerner \& Nelson, 1977; Cushman \& Kovacic, 1995).

\section{Theory as Puzzle-Making or Map- Making}

In The Social Construction of Reality, Peter Berger and Thomas Luckmann (1966) remark:

The human organism lacks the necessary biological means to provide stability for human conduct. Human existence, if it were thrown back on its organismic resources by themselves, would be existence in some sort of chaos. Such chaos is, however, empirically unavailable, even though one may theoretically conceive of it. Empirically, human existence takes place in a context of order, direction, stability. The question then arises: From what does the empirically existing stability of human order derive? An answer may be given on two levels. One may first point to the obvious fact that a given social order precedes any individual organismic development. That is, world-openness, while intrinsic to man's biological make-up, is always preempted by social order. One may say that the biologically intrinsic world-openness of human existence is always, and indeed must be, transformed by social order into a relative world-closedness (p. 51)

Berger and Luckmann (1966) reject the assimilation of the human setting with the physical habitat, and propose that the human environment, "with the totality of its socio-cultural and psychological formation," is produced and reproduced by human collectivities. In this conceptualization, "social order is a human product," "an ongoing human production," constructed by individuals in groups in the process of their externalization. "Social order is not part of the 'na- ture of things' and it cannot be derived from the "laws of nature"' (pp. 51-55). In this view, theoretical and practical knowledge, "constructed by people and transmitted through habitualization, is fixated into the objective reality" through institutionalization and is promoted as the truth (or even the ultimate truth) through the functioning of institutional stances. "The institutional world is objectivated human activity, and so is every single institution" (pp. 59-61).

Although the idea of theory as puzzle-making or map-making (puzzles or maps not made and given by higher authorities or impersonal stances, but produced and manipulated by humans) is an ancient one, it has been marginal through the history of the Western world and dismissed by mainstream modern philosophers and scientists as lacking rigor and precision. Yet, the notions that reality, knowledge, nature, and society are made up by human beings, that various individuals construct different narratives, and that official hierarchies of such stories are naturalized and commodified by groups and organizations, have survived (see Hayek, 1958; Adorno, 2000). Theory as puzzle-making or map-making is linked to the awareness and acknowledgment that objects of study are fabricated by and dependent on a theorist or researcher, a circle of scholars, or a tradition of theory and research; this type of theory is connected with critiques of the dichotomy between an object of study and a studying subjectivity, between a known and a knower, and efforts to abandon such dichotomies (see Bourdieu \& Wacquant, 1992). Theory as puzzle-making or map-making is an oppositional approach, one that challenges status-quo and questions the settled, one that calls for cross-disciplinary readings and trans-disciplinary flexibility.

The idea of the theory-maker as a puzzlemaker or map-maker, as someone who separates a certain fragment of life and treats it as a unity, as someone who asks questions about that specific unity and strives to conceptualize its logic, has made its place in communication studies, struggling against the dominant scientific and analytic trends. Critiquing theory as problem-solving, Deetz (1992) affirms: "All current theories will pass in time. It is not as if they are in error, at least little more or less so than those in the past. They were useful in handling differ- 
ent kinds of human problems, problems we might find ill-formed or even silly, as others will ours" (p. 77). Gandy (1993) professes: "The development of theory is a political act. It is purposeful, strategic, and tactical" (p. 383). Julia T. Wood (2004) asserts that "theories are human constructions" that are "neither objective descriptions of realities nor necessarily true" but that "represent points of view" (p. 31). Sue Curry Jansen (2002) declares: "I endorse an epistemological stance that conceives of knowledge as the unique and extraordinary achievement of embodied humans, not the work of gods. This stance rejects correspondence theories of truth that cast the scientist, poet, or scholar in the role of a privileged intermediary who speaks for God or Nature. That is, it calls my mind back to the body and struggles against Western dualism" ( $p$. 14).

In what follows, we will examine the two varieties of theory as puzzle-making or map-making, interpretation (selection-making) and inquiry (question-making).

\subsection{Interpretation (Selection-Making)}

We use the term "interpretation" as referring to the type of conceptualization that emerged from multiple directions in the modern Western world: the philosophy of Giambattista Vico, who argued for the study of culture rather than of nature; the philosophy of German idealism, that advocated the abandonment of objectivity and the embracement of subjectivity; the romanticist trends in the humanities, that fought against the oppression of laws and norms and that promoted creativity and imagination; the impressionist tendencies in the arts, that opposed academism and methodologization and that praised freedom and mixture (see Barzun, 2001); and several orientations in social theory, that proposed the approach of the particular rather than the general (see Gouldner, 1970, 1979). The definition of theory as interpretation is connected with attempts to grant authenticity and legitimacy to a multitude of cultural practices and of subjective experiences, against the universalizing and generalizing approaches that shaped and restrained Western thought. According to such conceptions, there is no single unique and absolute truth from which theories emerge, and there is no single and correct cognition of "reality." Interpretation is oriented towards exploring and understanding rather than towards prediction or prescription (see Ricoeur, 1974).

The definition of theory as interpretation gained importance in the Western world due to a crisis of understanding and to a reconsideration of science. The crisis of understanding was marked by a change of focus from the production and consumption of knowledge, the scientific explosion and the technological boom, to the evaluation and confrontation of knowledge, in terms of the "sense of purpose or direction," of the question "why?" or "what is the point?" The reconsideration of science was marked by a paradigm shift within the sciences, from considering the universe as fixed and absolute to viewing it as flexible and relative, from identifying measurement with exactness and precision to recognizing it as artificiality and intrusion (Dallmayr \& McCarthy, 1977).

For advocates of theory as interpretation, there is no all-encompassing science, and there are no sets of investigative instruments that guarantee reliability and provide certainty. Different people or groups of people, operating under diverse assumptions or within diverse belief systems, conceptualize different realities and articulate various bodies of knowledge. The promoters of theory as interpretation have themselves been assigned to and have themselves crossed different schools and circles: hermeneutics, that promotes subjective Verstehen instead of objective explanation, and treats all forms of existence as texts instead of truths, ideals, facts, or data; phenomenology, that highlights intentionality instead of reason, and being in the world instead of isolating from the world; pragmatism, that focuses on reality as change and transition rather than fixity and stability, and on knowledge as a means of adaptation to change and of attaining goals rather than of reaching the pure truths or facts (see Hallman, 2003).

If theory is interpretation, theoretical concepts are constructs arranged in clusters according to individual interests, group policies, social values, or cultural traditions, and then reified because of 
use and abuse. In this view, the characteristics of theories are confinement to time and space, and cultural and social limitation, and the roles of theories are organization, intelligibility, and sense-attribution to or sense-making of the human experience. If theory is interpretation, then any imaginable strategy of experiencing is valid, and any possible technique of study is appropriate. Knowledge is not confined to gods or to experts, and knowledge production is not confined to deduction and induction. It is impossible to separate theory from practice, universal from particular, reason from intuition, or public from private.

We are providing a number of examples concerning interpretivist theoretical concepts, characteristics of theories, roles of theories, and theoretico-methodological formulations. But we are aware (as should be the reader) that these are individual cases and particular projects, since interpretivists reject universalizations and essentializations. Past theoretical constructions and methodological proposals can constitute guides and signposts for future scholarship, but they can not replace involvement in and with an experience, in a study.

Hermeneutical philosopher Wilhelm Dilthey (1989) identified as the domain of human inquiry Geist, and as the way of human examination Verstehen; he distinguished Geist (translated as "culture" or "spirit") from nature, as well as Verstehen (translated as "interpretation" or "understanding") from explanation in terms of causal laws or empirical rules. For phenomenological philosopher Martin Heidegger (1962), being is never abstract or general, it is always concrete, the being of a being; that is why understanding, or access to being, can never be an abstraction or a generalization, it can only be particular, rooted in time. In the view of pragmatist scholar John Dewey (1927), traditional theories, both rationalist and empiricist, artificially separated the universe of fact from the realm of thought, thus denying thought any relevance to the world and devoiding thought of practical value.

Philosopher Hans-Georg Gadamer (1975) argued that "truth" and "method" are at odds with one another, that humans have a "historically effected consciousness," and that people are shaped by culture. Sociologist Peter Winch (1958; 1987) fought against viewing humans and their universes "from the outside," as physical objects of scientific treatment, and advocated for regarding humans and their realms "from the inside," in terms of "language-games" for interpretive treatment. Barney Glaser and Anselm Strauss (Glaser \& Strauss, 1967; Glaser, 1978; Strauss, 1987) have formulated "grounded theory" as a scholarly methodology, distinguishing between "forcing" research that tests a takenfor-granted and unquestioned hypothesis, and "emergent" research that constructs an internalized and challenged thesis. Clifford Geertz (1975) has developed cultural interpretation as a scholarly methodology, distinguishing between "thin descriptions," attempts at "discovering the Continent of Meaning and mapping out its bodiless landscape" (p. 20), and "thick descriptions," attempts at interpreting densely textured experiences and disclosing the "symbolic templates" of geographically and historically bound cultures (p. 216). The key words in this array of approaches are constructs or situated concepts, selection or choice and change, experience, or practice mixed with understanding, and intelligibility or subjective, intersubjective, institutional, or cultural ordering.

Promoters of theory as interpretation have been critiqued from one side by supporters of theory as science and investigation, not only for relativizing knowledge (an expected objection), but also for referring to and building on something inaccessible, internal experiences. Promoters of theory as interpretation have also been critiqued from the other side by advocates of theory as inquiry, for exposing settled conventions without challenging these customs and without proposing change in custom, for conceptualizing a multiplicity of voices without confronting the hierarchy of perspectives and without recommending change in order.

Theory as interpretation, adopted by some communication scholars, has been conceived as a way and a means of promoting both/and instead of either/or explanations in the social and cultural areas. Leonard C. Hawes (1977) conceptualizes a phenomenological approach for critiquing the assumptions of the dominant scientific tendency, "uncritically taken for granted" (p. 32). Hawes suggests a shift from the static explanation of human works distant, as "there and then," to the dynamic interpretation of hu- 
man activities as close, as "here and now" ( $p$. 33). Stanley Deetz (1978) envisages a hermeneutical approach for escaping the naïveté of the dominant scientific trend, "largely unaware of its own prejudices" (p. 14). Deetz proposes a move from a "reproductive" view of understanding, trying to discover the correct or perfect meaning and to dismiss all other viewpoints as misunderstandings or prejudices, to a "productive" view of understanding, striving to enrich significance by addressing each perspective as positive prejudice. James Carey (1989), building on John Dewey's pragmatism, proposes cultural studies as a way out of the "neurotic quest for certainty" and away from the "effects tradition" (p. 89). Carey suggests that tradition will have to be reinterpreted and "the methods and techniques on the craft redeployed," as "intelligence continually overflows the constrictions provided by paradigms and methods" (pp. 93-94).

Communication scholars have occasionally mentioned that, if theories are interpretations, they can not have as features simplicity, testability, and replicability, and can not have as roles explanation, prediction, and control. Instead, an interpretive theory has as characteristics imaginative power, experiential value, and aesthetic appeal, and as uses new understandings and new meanings of people, of communities, and of values.

Advocates of theory as interpretation in communication studies have adapted or imagined methodologies for ensuring that theoretical underpinnings leave claims of universality and necessity and assume spatio-temporal and sociocultural circumscription, that theory becomes grounded sense-making and meaningattribution. Various authors have designed ethnographic and ethnomethodological strategies, have performed "thick descriptions," or have devised their own strategies. For example, Brenda Dervin $(1983,2003)$ has conceptualized sensemaking as a modality of identifying the specific communities that promote a particular vision, identifying alternative communities that promote different visions, thus expanding the repertoires of human understanding. Craig and Tracy (1995) have formulated grounded practical theory for providing "a reasoned basis for deliberating about, or critically evaluating particular communicative acts" (p. 248), and for describing "reflectively informed, morally accountable human action" (p. 249).

\subsection{Inquiry (Question-Making)}

We use the term "inquiry" as referring to a type of conceptualization that has permeated Western thought, from its historical beginnings to the contemporary period, as challenging, critical, oppositional, disruptive, or subversive. We associate the term "inquiry" with the shift from ideals of accumulation (of truths, facts, or even individual and cultural selections) to logics of discontinuity, from utopias of progress to practices (even if sometimes dystopian) of regression. If theory as interpretation offered a framework for escaping univocity towards pluralism, theory as inquiry provides a framework for departing from univocity and pluralism for difference.

The word "inquiry" has been employed in theory as science, yet it has meant questions posed from an absolute impersonal stance; it has been used in theory as investigation, but it has signified questions agreed upon by an elitist scholarly community; and it has been utilized in theory as interpretation, where it has designated the vivid curiosity of the interpreter that provokes experience and illuminates meanings. Yet to identify theory with questioning, with inquiry means to uncover and demystify the practices by which theory becomes a process of choosing questions according to theorist's interests, and of providing answers to the questions according to the theorist's background and body of knowledge.

The theory-maker as a question-maker is someone who is critically aware and empowers others to become critically aware that theory separates a certain fragment of the world (or of life) and treats it as a unity (with or without acknowledging the limitations of her/his own perspective), as that theory asks specific questions about that specific unity and strives to conceptualize its logic. We consider that theorizing as inquiry is the transformation of a set of axioms (viewed by a theorist or a school of thought to be beyond disputation) into a series of questions (presented by a theorist or a group of theorists as being entirely disputable), followed by the 
adaptation of the responses or theoretical positions to the questions or areas of inquiry. We also consider that theorizing as inquiry uncovers that its own construction is made of replies to something (to a body of pre-established and assumed body of knowledge) rather than of statements about something (a reality), and constitutes various reports and relations rather than the Truth or the path to it.

If theory is inquiry, theoretical concepts are selections or decoupages made according to spatio-temporal, economic, socio-political, and cultural contexts, and critically recognized to be just that. In this view, the characteristics of theories are situatedness in terms of historicity and geopolitics as well as in terms of centrality or marginality, and the roles of theories are uncovering power relations and empowering those oppressed. If theory is inquiry, then the appropriate methodology associated with it is the critique - the critical examination of the self and of otherness, and of how reality and knowledge are formed and transformed in the nexus of power.

Peter Brooker (1999) affirmed: "Theory is of use if it problematizes taken-for-granted attitudes and positions (on theory itself as much as anything else) and conceptualizes long-standing or new issues in a productive way. The important thing is that 'living theory,' as it might be termed, frames questions and informs our thinking and hence our activity in a range of academic and social areas," (p. vii). Although often dismissed by promoters of theory as science and as investigation as too personal and too political, advocates of theory as inquiry are skeptical of the preservation and reification of dominant meanings anywhere and at any time, in their own lives as well as in others' practices, in institutions as well as out on the streets.

The advocates of theory as inquiry view "truth" as related to power, as in close but secret connection with those who have authority or the right to speak (in private, in public, in the media, etc.), and view "reality" as linked to conquest, to domination, to colonization, to totalitarian tendencies (in and out of the Western world). The supporters of theory as inquiry contend that bodies of knowledge and research methodologies, old and new, have been and are being too easily and too often employed as perfidious instru- ments of social uniformization and of political control.

The advocates of theory as inquiry have developed critical discussions of generalization and universalization. In such a view, generalized and universalized theories of society do not provide grounds for explaining the organization of society, but rather grounds for imposing the organization of society as desired by the powerful of the day. In such a perspective, generalized and universalized theories of communication study do not contribute to the understanding of the voices of the people, but impose an understanding of the voice of a standardized and voided majority and that marginalizes and excludes minority groups and opposition trends. Schools of thought as diverse as British cultural studies and French poststructuralism have affirmed that textual studies, uncovering and comparing particular sets of histories and alliances, should replace the same analytic framework used to study all times, all places, and all people. From such perspectives, feminist scholars have provided not only critiques of patriarchy but also critiques of the representative "woman", and race theorists have discussed not only racial and colonial oppression but also the different responses (or lack of response) to oppression on different continents and countries, at different points in time. Ethical issues related to the accountability of the theorist to the theorized, of the researchers to the researched, have been raised.

In "The Rediscovery of Ideology: The Return of the Repressed in Media Studies" (1982) and in "Ideology and Communication Theory" (1989), Stuart Hall states that sometime in the second part of the $20^{\text {th }}$ century there has been a shift from a mainstream way of theorizing communication, which has been positivist and hegemonic, to an alternative way of defining, interpreting and reflecting on communication, that accounts for ideology and does not endorse the power structures of a particular place, time, society or culture. Hall's depiction of transformation in communication theories is a depiction of the movement toward theory as inquiry. In Hall's opinion, the shift was started by such analysts of cultural phenomena as Claude Levi Strauss and Roland Barthes, who question cultural categories but still universalize them, and was contin- 
ued by diverse thinkers emerging from Marxist studies and cultural studies, who question cultural categories and avoid their universalization. Stuart Hall gives the example of Adorno and Horkheimer, who looked at ways in which the culture industries in some respects support the status quo and contribute to the supremacy of the power elites, and in some other respects have potential to become subversive and to be used by oppressed groups against the status quo and the power elites; Hall also offered examples from the Birmingham cultural studies group, discussing the negotiation of class by various people and groups of people (Raymond Williams), and approaching the negotiation of mediated romance by different women (Janice Radway). Other examples, outside of the areas discussed by Stuart Hall, could be the discussion of technology as gendered by a number of feminist theorists (summarized in Jansen, 2002), and the discussion of history as raced by several critical race theorists (summarized by West, 1994).

\section{Conclusions}

In the "Post-word" to the book Post-Theory, Hélène Cixous (1999) offers a series of halfparodic and half-serious definitions and interpretations of the term and notion of theory:

"Théorie:

1. In French (not pronounced at all like Theory in English) is pronounced: Thé au riz. Can also be read: Théo rit.

2. Feminine noun like Philosophie.

3. Name of the god of Humor often represented as the cat of a great philosopher.

4. Fiction.

5. Additional word that has ambiguous fortunes during the twentieth century in English-speaking countries" (p. 210)

What Hélène Cixous ironically implies is that there is a concreteness in terms of place and gender for a theoretical position (for her, theory is French and feminine, as she is a French woman), and that the ideals of theoretical universalism and of essentialism should be, if not abandoned, then approached with a laughter: a theory is not the truth but one of the multiple fictions, the central character of a theory is not a great philosopher but the god of Humor (the cat of a great philosopher), the history of theories and discourses about theories is ambiguous.

What the present essay implies, in agreement with Hélène Cixous, is that theories should be decoded in a flexible and creative manner, allowing potentialities to blossom. In this we share Craig's (2007) dialogic-dialectical goal of theory classification. Our taxonomy departs significantly, however, from those proposed by most authors, in that we see the value and importance of viewing theoretical positions through their employment of concepts, features, and methods, as well as through their approach to the subject-object relationship. This enables us to consider the viewpoint of the theorist and the status of the subject of inquiry, further developing Rosengren's (2000) taxonomy of subjectobject, consensus-conflict (adapted from Burrell and Morgan,1979). We have avoided characterizations by lineage (e.g. Craig 2007) because these tend to reify claims already made about such traditions, glossing over presuppositions, and by level (e.g. McQuail 2005) because these reify distinctions among certain communication phenomena rather than examining the reasons for distinctions among theories developed about certain phenomena and not about others.

Most dramatically, our position rejects the characterization by DeFleur of two types of theory, one derived from research and the other from ideology. In our view, different theories operate with different types of definitions, expressions, ideologies, and research assumptions and practices. We have pressed for the idea that theories in communication stem from two main approaches: puzzle-solving, with its two variations of science (truth-seeking) and investigation (fact-seeking); and puzzle-making, with its two variations of interpretation (selection-making) and inquiry (question-making). Scientific theory conveys a belief in laws, universality, measurement, and control, whereas investigative theory relies on rules, conventionality, observation, and prescription. Interpretive theory conveys a belief in the multiplicity of people, cultures, and means of knowing and understanding, whereas inquisitive theory is grounded in difference (in terms of race, ethnicity, gender, sexuality, centrality and marginality, etc.), as well as in skepticism (about both the possibility of knowledge and the capabilities of power). The puzzle-solving approach assumes that the phenomenon exists apart from the meanings and intentions of the one who de- 
fines and examines the problem, and hence frames the potential solutions. The puzzlemaking approach, which uncovers the meanings and the means of theorizing itself, assumes that the observer cannot be separated from the phenomenon, and hence multiple possibilities are open.

While other authors of classifications of communication theories have opted to remain dispassionate in their conclusions about various theoretical positions, we have departed, too, from this convention. Like DeFleur's undisguised disapproval of "ideological" positions, we have opted to convey our understanding of what theory is, not in a neutral manner, but with our disagreements and sympathies revealed. We consider it important to disclose and affirm our preference for theory as puzzle-making or mapmaking, particularly our closeness to theory as inquiry. Perhaps restoring the meaning of theorein as "passionate sympathetic contemplation" (Russell 1979, p. 52) or adopting Cixous's antidote of laughter at the multiple fictions mistaken for Truth should not so easily be dismissed.

\section{References}

Adorno, T.W., Ed. [1976] (1994). The Positivist Dispute in German Sociology. Brookfield, VT: Avebury.

Agassi, J. (1975). Science in Flux. Dordrecht, Netherlands: Reidel.

Anderson, R. \& Ross, V. (1994). Questions of Communication: A Practical Introduction to Theory. New York, NY: St. Martin's.

Archer, M. (1995). Realistic Social Theory: The Morphogenetic Approach. Cambridge, MA: Cambridge University Press.

Baldwin, J.R., Perry, S.D., \& Moffitt, M.A. (2004). Communication Theories for Everyday Life. New York, NY: Pearson.

Barnes, J., Ed. (1995). The Cambridge Companion to Aristotle. Cambridge, MA: University of Cambridge Press.

Barzun, J. (2001). From Dawn to Decadence: 500 Years of Western Cultural Life, 1500 to the Present. New York, NY: HarperCollins.

Benton, T. \& Craib, I. (2001). Philosophy of Social Science: The Philosophical Foundations of Social Thought. New York, NY: Palgrave.

Berger, C.R. (1977). The Covering Law Perspective as a Theoretical Basis for the Study of Human Communication. Communication Quarterly, 25(1), 7-18.

Berger, C.R. \& Chaffee, S.H. Eds. (1987), Handbook of Communication Science. Newbury Park, CA: Sage.

Berger, P.L. (1963). Invitation to Sociology: A Humanistic Perspective. New York, NY: Doubleday.

Berger, P.L. \& Luckmann, T. (1966). The Social Construction of Reality: A Treatise in the Sociology of Knowledge. New York, NY: Doubleday.

Berlin, I. (1996). The Sense of Reality: Studies in Ideas and Their History. New York, NY: Farrar, Straus, \& Giroux.

Berlo, D. K. (1977). Communication as Process: Review and Commentary. Communication Yearbook, 1, 11-27.

Bhaskar, R. (1979). The Possibility of Naturalism. Hemel Hempstead, UK: Harvester.

Blalock, H.M. (1969). Theory Construction: From Verbal to Mathematical Formulations. Englewood Cliffs, NJ: Prentice Hall.

Burrell, G. \& Morgan, G. (1979). Sociological Paradigms and Organisational Analysis. London, UK: Heineman.

Cajete, G. (2000). Native Science: Natural Laws of Interdependence. Santa Fe, NM: Clear Light.

Carey, J. W. (1989). A Cultural Approach to Communication. In J. W. Carey, Communication as Culture (pp. 13-36). Boston, MA: Unwin Hyman.

Carnap, R. [1934]. 1995. The Unity of Science. Bristol, UK: Thoemmes.

Carnap, R. (2003). The Logical Structure of the World: Pseudoproblems in Philosophy. Chicago, IL: Open Court.

Cartwright, N. (1989). Nature's Capacities and Their Measurement. Oxford, UK: Clarendon.

Casmir, F.L.(1994). Building Communication Theories: A Socio/Cultural Approach. Hillsdale, NJ: Lawrence Erlbaum.

Chafee, S.H. (1996). Thinking about Theory. In M.B. Salwen \& D.W. Stacks (Eds.). An Integrated Approach to Communication Theory and Research (pp. 15-32). Mahwah, NJ: Lawrence Erlbaum.

Cohen, M.R. (1931). Reason and Nature, an Essay on the Meaning of Scientific Method. New York, NY: Harcourt, Brace, \& Co.

Compte, A. (1854). The Positive Philosophy of Auguste Compte. London, UK: Chapman.

Cragan, J.F. \& Shields, D.C. (1998). Understanding Communication Theory: The Communicative Forces for Human Action. Boston, MA: Allyn \& Bacon.

Craig, R.T \& Tracy, K. (1995). Grounded Practical Theory: The Case of Intellectual Discussion. Communication Theory, 5, $242-272$.

Craig, R.T. (2007). Communication Theory as a Field. In Robert T. Craig \& Heidi L. Muller (Eds.). Theorizing Communication: Readings Across Traditions (pp. 63-98). Thousand Oaks, CA: Sage.

Cushman, D. P. \& Kovacic, B. (1995). Watershed Research Traditions in Human Communication Theory. Albany: State University of New York Press. 
Cushman, D.P. \& Pearce, W.P. (1977). Generality and Necessity in Three Types of Human Communication Theory: Special Attention to Rules Theory. Communication Yearbook, 1, 173-182.

Cushman, D. \& Whiting, G.C. (1972). An Approach to Communication Theory: Toward Consensus on Rules. Journal of Communication. 22(3), 217-238.

Dallmayr, F.R. \& McCarthy, T.A. (1977), Understanding and Social Inquiry. Notre Dame, IN: University of Notre Dame Press.

Dance, F.E.X. \& Larson, C.E. (1976). The Functions of Human Communication: A Theoretical Approach. New York, NY: Holt, Rinehart, \& Winston.

Deetz, S.A. (1992). Democracy in an Age of Corporate Civilization: Developments in Communication and the Politics of Everyday Life. Albany, NY: Sunny Press.

DeFleur, M.L. \& DeFleur, M. (2010). Mass Communication Theories: Explaining Origins, Processes, and Effects. New York, NY: Allyn \& Bacon.

Delia, J.G. (1987). Communication Research: A History. In C.R. Berger \& S.H. Chafee (Eds.). Handbook of Communication Science (pp. 20-98). Newbury Park, CA: Sage.

Denzin, N.K. \& Lincoln, Y.S. (2003). The Landscape of Qualitative Research: Theories and Issues. Thousand Oaks, CA: Sage.

Dewey, J. (1927). The Public and Its Problems. New York, NY: Holt.

Diesing, P. (1991). How Does Social Science Work? Reflections on Practice. Pittsburg, PA: University of Pittsburg Press.

Dilthey, W. (1985). Selected Works. Princeton, NJ: Princeton University Press.

Dubin, R. (1969). Theory Building. New York, NY: Free Press.

Edel, A. (1982). Aristotle and His Philosophy. Chapel Hill, NC: University of North Carolina Press.

Feyerabend, P. [1975] (1994). Against Method. New York, NY: Verso.

Feigl, H. \& Brodbeck, M., Eds. (1953). Readings in the Philosophy of Science. New York, NY: Appleton-Century-Crofts.

Foucault, M. (1965). Madness and Civilization: A History of Insanity in the Age of Reason. New York, NY: Pantheon Books.

Foucault, M. (1972). The Archaeology of Knowledge. New York, NY: Harper \& Row.

Gadamer, H.G. (1975). Truth and Method. New York, NY: Seabury.

Gandy, O.H. (1993). On Building Theory from the Inside Out. Communication Yearbook, 16, 381-395.

Ganz, J. (1971). Rules: A Systematic Study. The Hague, Netherlands: Mouton.

Garber, L. (2001). Identity Poetics: Race, Class, and the Lesbian-Feminist Roots of Queer Theory. New York, NY: Columbia University Press.

Geertz, C. [1973] (1975). The Interpretation of Cultures. London, UK: Hutchinson.

Geertz, C. (1983). Local Knowledge: Further Essays in Interpretive Anthropology. New York, NY: Basic Books.

Gibbs, J.P. (1972). Sociological Theory Construction. Hinsdale, IL: Dryden.

Giddens, A. (1989). The Orthodox Consensus and the Emerging Synthesis. In B. Dervin, L. Grossberg, B.J. O'Keefe, \& E. Wartella, Rethinking Communication. Volume 1: Paradigm Issues (pp. 53-65). Newbury Park, CA: Sage.

Gitlin, T. (1978). Media Sociology: The Dominant Paradigm. Theory and Society, 6, 205-253.

Glaser, B. \& Strauss, A. (1967). The Discovery of Grounded Theory: Strategies for Qualitative Research. Chicago, IL: Aldine.

Glaser, B.G. (1978). Theoretical Sensitivity: Advances in the Methodology of Grounded Theory. Mill Valley, CA: Sociology Press.

Gouldner, A.W. (1970). The Coming Crisis of Western Sociology. New York, NY: Basic Books.

Griffin, E. [1991] (2000). A First Look at Communication Theory. Boston, MA: McGraw Hill.

Habermas, J. (1998). On the Logic of the Social Sciences. Cambridge, MA: MIT Press.

Habermas, J. (1989). The Structural Transformation of the Public Sphere. Cambridge, MA: MIT Press.

Hall, S. (1982). The Rediscovery of "Ideology:" Return of the Repressed in Media Studies. In M. Gurevitch, T. Bennett, J. Curran \& J. Wollacott (Eds.), Culture, Society, and the Media (pp. 56-90). London: Methuen.

Hall, S. (1989). Ideology and Communication Theory. In B. Dervin, L. Grossberg, B. J. O'Keefe, \& E. Wartella (Eds.), Rethinking Communication: Paradigm Issues. Volume 1. (pp. 40-52). Newbury Park, CA: Sage.

Hanna, J.F. (1982). Two Ideals of Scientific Theorizing. Communication Yearbook, 5, 29-47.

Haraway, D. (1989). Primate Visions: Gender, Race, and Nature in the World of Modern Science. New York, NY: Routledge.

Harding, S. (1986). The Science Question in Feminism. Ithaca, NY: Cornell University Press.

Hardt, H. (1992). Critical Communication Studies: Communication, History and Theory in America. New York, NY: Routledge.

Heath, R.L. \& Bryant. J. (2000). Human Communication Theory and Research: Concepts, Contexts, and Challenges. Mahwah, NJ Lawrence Erlbaum.

Hempel, C. (1952). Fundamentals of Concept Formation in the Empirical Science. Chicago, IL: University of Chicago Press.

Hollis, M. (1994). The Philosophy of Social Science: An Introduction. New York, NY: Cambridge University Press.

Horkheimer, M. \& Adorno, T.W., Eds. (1956). Aspects of Sociology. By the Frankfurt Institute for Social Research. Boston, MA: Beacon.

Infante, D.A., Rancer, A.S., \& Womack, D.F. [1990] (2003). Building Communication Theory. Prospect Heights, IL: Waveland. Jackson, J.P., Ed. (2002). Science, Race and Ethnicity: Readings From Isis and Osiris. Chicago, IL: University of Chicago Press. Jansen, S.C. (2002). Critical Communication Theory: Power, Media, Gender and Technology. New York, NY: Rowman \& Littlefield. Kaplan, A. (1964). The Conduct of Inquiry: Methodology for Behavioral Science. San Francisco: Chandler. 
Keller, E.F. (1985). Reflections on Gender and Science. New Haven, CT: Yale University Press.

Knorr-Cetina, K. \& Cicourel, A.V., Eds. (1981). Advances in Social Theory and Methodology: Towards an Integration of Micro- and Macro- Sociologies. London, UK: Routledge.

Kochen, M. (1979). Behavioral Sciences and Communication Sciences: In Search of Basic Principles. In M.J. Voigt \& G.J. Hanneman (Eds.), Progress in Communication Sciences. Volume 1. Norwood, NJ: Ablex.

Krippendorff, K (1977). Information Systems Theory and Research: An Overview. Communication Yearbook, 1, 149-171.

Kuhn, T. [1962] (1996). The Structure of Scientific Revolutions. Chicago, IL: University of Chicago Press.

Lakatos, I. \& A. Musgrave (1968). Problems in the philosophy of science. Amsterdam, Netherlands: North-Holland Publishers.

Lakatos, I. (1978). The Methodology of Scientific Research Programs. New York, NY: Cambridge University Press.

Lerner, D. \& Nelson, L.M. (1977). Communication Research: A Half-Century Appraisal. Honolulu: University of Hawaii Press.

Littlejohn, S.W. [1978] (2002). Theories of Human Communication. Belmont, CA: Wadsworth.

Littlejohn, S.W. \& Foss, K.A. (2005). Theories of Human Communication. New York, NY: Thomson Wadsworth.

Losee, J. (1987). Philosophy of Science and Historical Inquiry. New York, NY: Oxford University Press.

Machamer, P.K. \& Silberstein, M. (2002). The Blackwell Guide to the Philosophy of Science. Malden, MA: Blackwell.

McGuire, W.J. (1981). Theoretical Foundations of Campaigns. In R.E. Rice \& W.J. Paisley (Eds.), Public Communication Campaigns (pp.41-70). Newbury Park, CA: Sage.

McQuail, Denis. [1983] (2005). McQuail's Mass Communication Theory. Newbury Park, CA: Sage.

Miller, G.R. \& Berger, C.R. (1978). On Keeping the Faith in Matters Scientific. Western Journal of Speech Communication, 42, 5758.

Miller, K. [2002] (2005). Communication Theories: Perspectives, Processes, and Contexts. Boston, MA: McGraw Hill.

Miller, G.R. \& Nicholson, H.E. (1976). Communication inquiry: A perspective on a process. Reading, MA: Addison-Wesley.

Mischel, T. (1969). Human Action: Conceptual and Empirical Issues. New York, NY: Academic Press.

Monge, P.R. (1977). The Systems Perspective as a Theoretical Basis for the Study of Human Communication. Communication Quarterly, 1977(1), 19-29.

Mullins, N.C. (1971). The Art of Theory Construction and Use. New York, NY: Harper \& Row.

Nagel, E. (1952). Some Issues in the Logic of Historical Analysis. The Scientific Monthly, 74(3), 162-169.

Nathanson, M., Ed. (1963). Philosophy of the Social Sciences. New York, NY: Random House.

Oppenheim, P. \& Putnam, H. [1958] (2000). Unity of Science as a Working Hypothesis. In T. Schick (Ed.). Readings on the Philosophy of Science: From Positivism to Postmodernism. Mountain View, CA: Mayfield.

Peters, J.D. (1986). Institutional Sources of Intellectual Poverty in Communication Research. Communication Research, 13(4), 527559.

Phillips, D.C. (1992). The Social Scientists' Bestiary: A Guide to Fabled Threats to, and Defenses of, Naturalistic Social Science. New York, NY: Pergamon.

Philipsen, G. (1993). Ritual as a Heuristic Device in Studies of Organizational Discourse. Communication Yearbook, 16, $104-112$.

Popper, K. [1959] (2002). The Logic of Scientific Discovery. New York, NY: Routledge.

Reynolds, P.D. (1971). A Primer in Theory Construction. New York, NY: Bobbs-Merrill.

Ricoeur, P. (1971). The Model of the Text: Meaningful Action Considered as a Text. Social Research, 38(3), 529-562.

Rosengren, K.E. (2000). Communication: An Introduction. Newbury Park, CA: Sage.

Russell, B. [1945] (1979). History of Western Philosophy. New York, NY: Simon and Schuster.

Schick, T., Ed. (2000). Readings in the Philosophy of Science: From Positivism to Postmodernism. Mountain View, CA: Mayfield.

Schramm, W.L. (1963). The Science of Mass Communication: New Directions and New Findings in Communication Research. New York, NY: Basic Books.

Sedgwick, E.K. (1990). The Epistemology of the Closet. Berkeley, CA: University of California Press.

Shimanoff, S.B. (1980). Communication Rules: Theory and Research. Beverly Hills, CA: Sage.

Smith, T.J. (1988). Diversity and Order in Communication Theory: The Uses of Philosophical Analysis. Communication Quarterly, $36(1), 28-40$.

Stinchcombe, A.L. (1968). Constructing Social Theories. New York, NY: Harcourt, Brace, \& World.

Stacks, D.W., Hill, S.R., Jr., \& Hickson, M. III, (1991). An Introduction to Communication Theory. Chicago, IL: Holt, Rinehart, \& Winston.

Subramaniam, M. \& Weasel, L.H., Eds. (2001). Feminist Science Studies. New York, NY: Routledge.

Sullivan, N. (2003). A Critical Introduction to Queer Theory. New York, NY: New York University Press.

Toulmin, S.E. (1953). The Philosophy of Science: An Introduction. New York, NY. Hutchinson's University Library.

Toulmin, S.E. (1990). Cosmopolis: The Hidden Agenda of Modernity. New York, NY: Free Press.

Turner, B.S., Ed. (1996). The Blackwell Companion to Social Theory. Malden, MA: Blackwell.

Vico, G. (1968). The New Science. Ithaca, NY: Cornell University Press.

Vico, G. (1982). Selected Writings. New York, NY: Cambridge University Press.

West, R.L. \& Turner, L.H. (2000). Introducing Communication Theory: Analysis and Application. Mountain View, CA: Mayfield.

Willer, D. (1967). Scientific Sociology. Englewood Cliffs, NJ: Prentice Hall. 
Williams, R. (1976). Key Words: A Vocabulary of Culture and Society. New York, NY: Oxford University Press. Winch, P. (1958). The Idea of Social Science and Its Relation to Philosophy. New York, NY: Routledge. Wittgenstein, L. (1922). Tractatus Logico-Philosophicus. New York, NY: Harcourt, Brace \& Co. Wittgenstein, L. (1953). Philosophical Investigations. New York, NY: Macmillan.

Wood, J.T. (1997). Communication Theories in Action: An Introduction. Belmont, CA: Wadsworth.

Woolgar, S. (1988). Science: The Very Idea. London, UK: Tavistock.

Zetterberg, H.L. (1954). On Theory and Verification In Sociology. New York, NY: Tressler Press.

\section{About the Authors}

Diana Nastasia

Diana Nastasia is currently working towards a Ph.D. in Communication and Public Discourse at the University of North Dakota as well as towards a Ph.D. in Literary Theory at the University of Bucharest. She earned an M.A. in Comparative Literature and Literary Theory (1996), and B.A.s in Modern Languages and Literatures (1995) and in Philosophy (1997), all from the University of Bucharest, Romania. In her home country, she was a lecturer then an assistant professor at the Romanian-American University and at the National School of Political Studies and Public Administration in Bucharest. She came to the United States as a Fulbright visiting researcher in 2002. Recently, she has been the associate editor of Community Connect: The Journal of Civic Voices produced by the University of North Dakota Center for Community Engagement, and the regional coordinator for Eastern Europe of the project "Global Report on Gender in the News Media" conducted by the International Women's Media Foundation. She has been elected Student Representative for 2010-2012 on the Board of Directors of the International Communication Association.

Lana F. Rakow

Lana F. Rakow is a professor of communication at the University of North Dakota, where she also is the founder and director of the Center for Community Engagement. She earned a Ph.D. degree from the University of Illinois, Champaign-Urbana Institute of Communications Research in cultural studies and feminist theory. She also has an M.A. degree in English (American Literature and language) and a B.A. degree (journalism and humanities) from the University of North Dakota. Among her four published books is Feminist Communication Theory (Sage), co-edited with Laura Wackwitz. Rakow is the author of many other articles and special research reports on gender, technology, theory and research, community, and higher education curricula. 